\title{
Repeated haloperidol increases both calmodulin and a calmodulin-binding protein in rat striatum
}

\author{
Margaret E. Gnegy *, Alka Agrawal, Keiki Hewlett, Evan Yeung, Susan Yee \\ Department of Pharmacology, 7427 Medical Sciences I, University of Michigan Medical School, Ann Arbor, MI 48103-0626, USA
}

Accepted 12 July 1994

\begin{abstract}
Repeated treatment with the antipsychotic drug, haloperidol, leads to an increased behavioral sensitivity to dopamine agonists exhibited upon withdrawal from the drug. An increase in the particulate content of the endogenous $\mathrm{Ca}^{2+}$-binding protein, calmodulin, has been demonstrated after repeated treatment of rats with haloperidol. In this study, the anatomical specificity of the effect of repeated haloperidol treatment on the content and subcellular localization of calmodulin was investigated. Responsivity of calmodulin localization to dopaminergic input following drug treatment was assessed by determining the subcellular localization of calmodulin following an in vivo amphetamine challenge before sacrifice. Male, Sprague-Dawley rats were treated with $0.5 \mathrm{mg} / \mathrm{kg}$ haloperidol (s.c.) for 3 weeks and withdrawn from the drug for 4 days. Repeated haloperidol increased calmodulin content only in the striatum but altered the subcellular distribution of calmodulin in rat limbic forebrain and frontal cortex. In the latter areas, the soluble calmodulin was increased while the particulate calmodulin was decreased. There was no change in calmodulin in either hippocampus or cerebellum in response to drug treatment. Challenge with the dopamine mimetic, amphetamine, before sacrifice was effective in redistributing calmodulin only in striatum from rats that had been treated repeatedly with haloperidol, demonstrating an increased sensitivity of the translocation process. In order to determine whether a change in a calmodulin-binding protein would accompany the drug-induced increase in calmodulin, striatal calmodulin-binding proteins were examined using a biotinylated calmodulin overlay technique. Repeated haloperidol treatment enhanced calmodulin binding to a $150 \mathrm{kDa}$ protein in striatal membranes. The $150 \mathrm{kDa}$ protein exhibited the same gel mobility and subcellular distribution as myosin light chain kinase immunoreactivity. There was an increase in myosin light chain kinase immunoreactivity in striatal membranes after repeated haloperidol that was apparent in animals withdrawn either 4 or 10 days from haloperidol treatment. Therefore, repeated haloperidol could increase the rat striatal content of calmodulin and potentially that of the calmodulin-binding protein, myosin light chain kinase. Increases in striatal calmodulin and myosin light chain kinase may signal a greatly enhanced sensitivity of actin-myosin interactions after repeated haloperidol that could contribute to haloperidol-induced neurochemical or morphological changes involved in drug-induced synaptic plasticity.
\end{abstract}

Keywords: Calmodulin; Myosin light chain kinase; Biotinylated calmodulin; Translocation; Basal ganglia; Supersensitivity; Amphetamine; Antipsychotic drug

\section{Introduction}

Repeated treatment with antipsychotic drugs leads to an increased behavioral sensitivity to dopamine agonists and dopamine mimetic drugs exhibited upon withdrawal from the drug [52] and a time-dependent sensitization to antipsychotic drug-induced behaviors [1].

\footnotetext{
* Corresponding author.
}

Increased numbers or sensitivity of both pre- and postsynaptic dopamine receptors in rat striatum and limbic forebrain may contribute to the behavioral supersensitivity [7,47,55], but other expressions of synaptic plasticity undoubtedly contribute to the response. For example, repeated treatment with the dopamine antagonist, haloperidol, results in alterations in the ultrastructure of striatal and frontal cortical neurons that suggest increased number of synapses, possible sprouting of presynaptic neurons and induced postsynaptic changes [4,24-26]. 
We and others have previously reported an increase in the endogenous $\mathrm{Ca}^{2+}$-binding protein, calmodulin $(\mathrm{CaM})$, in striatum from rats treated with repeated haloperidol and other antipsychotic drugs $[15,18,29,42]$. $\mathrm{CaM}$ is a ubiquitous, multifunctional $\mathrm{Ca}^{2+}$-binding protein that acts as a $\mathrm{Ca}^{2+}$-dependent regulator of cyclic nucleotide metabolism, $\mathrm{Ca}^{2+}$-transport, protein phosphorylation-dephosphorylation cascades, ion transport, cytoskeletal function and cell proliferation [32,34]. The haloperidol-induced increase in striatal particulate CaM developed after withdrawal from the drug in a time dependent manner that correlated with the development and expression of apomorphine-induced stereotyped behavior [15]. The function of the drug-induced increase in CaM has yet to be elucidated but drug-induced changes in CaM activation of some target enzymes have been reported. Enhanced CaM-dependent phosphorylation in rat striatal membranes [28] and an increased sensitivity of striatal adenylyl cyclase to dopamine, GTP [15,23,36,48,53] and CaM [53] have been reported as a consequence of repeated haloperidol. CaM has been shown to synergistically increase the sensitivity of striatal adenylyl cyclase to dopamine and GTP $[13,19,38]$. The function of CaM can also be implied by its cellular or subcellular localization and selective changes in CaM binding proteins. CaM localization in rat striatum is responsive to dopaminergic activity. Both dopamine, acting through D-1 receptors, and amphetamine (AMPH) have been shown to elicit a redistribution of striatal $\mathrm{CaM}$ from membranes to cytosol in studies involving striatal membranes, slices or treatment of whole animals $[16,35,41,46]$. Translocation of CaM could lead to selective activation or deactivation of specific CaM-dependent target proteins, depending upon their location, and increased sensitivity of $\mathrm{Ca}^{2+} / \mathrm{CaM}$-dependent responses.

In this study, we investigated the anatomical specificity in rat brain of the haloperidol-induced increase in $\mathrm{CaM}$ and the subcellular localization of CaM following an in vivo amphetamine challenge. In order to determine whether a change in a CaM-binding protein would accompany the drug-induced increase in $\mathrm{CaM}$, striatal CaM-binding proteins were examined using biotinylated CaM overlay technique. Our results demonstrated that repeated haloperidol increased CaM content primarily in the striatum but altered the subcellular distribution of CaM in rat limbic forebrain and frontal cortex. Challenge with AMPH before sacrifice was effective in redistributing CaM only in striatum from rats that had been treated repeatedly with haloperidol, demonstrating an increased sensitivity of the translocating process. In addition to increasing $\mathrm{CaM}$ content in striatum, repeated haloperidol treatment enhanced CaM binding to a $150 \mathrm{kDa}$ protein in striatal membranes which correlated with increased myosin light chain kinase (MLCK) immunoreactivity.

\section{Materials and methods}

\subsection{Chronic treatment paradigm}

Male, Sprague-Dawley rats (Holtzman Inc., Madison WI), $200 \mathrm{~g}$, were injected i.p. with haloperidol (HAL) $(0.5 \mathrm{mg} / \mathrm{kg}$ s.c.) or vehicle (VEH) daily for 21 days. Vehicle consisted of $2 \%$ methanol and 0.8 $\mathrm{M}$ acetic acid, $\mathrm{pH}$ 7.0. Four days or, in one experiment, 10 days after the last dose of drug, rats received an injection of either saline (SAL) or AMPH ( $1 \mathrm{mg} / \mathrm{kg}$ i.p.) $30 \mathrm{~min}$ before sacrifice such that 4 groups were formed: VEH-SAL. VEH-AMPH, HAL-SAL, HAL-AMPH. All animals were sacrificed on the same day and the brain areas were dissected on ice, weighed and the tissue frozen in liquid $\mathrm{N}_{2}$. Brain areas were dissected using a brain cutting block as described by Heffner et al [20]. The limbic forebrain area contains both nucleus accumbens and olfactory tubercle. Medial prefrontal cortex was dissected, which was shown to have the highest concentration of DA $[20]$.

\subsection{Measurement of CaM content}

Tissue was prepared for measurement of $\mathrm{CaM}$ by homogenization in $40 \mathrm{mM}$ Tris, $\mathrm{pH} 7.4$ at $4^{\circ} \mathrm{C}$, containing $0.32 \mathrm{M}$ sucrose, $3 \mathrm{mM}$ $\mathrm{MgCl}_{2}, 1 \mathrm{mM}$ leupeptin, $1 \mathrm{mM}$ pepstatin and $1 \mathrm{mM}$ phenylmethylsulfonyl fluoride. Particulate (membrane) and cytosolic fractions were prepared by centrifugation at $100,000 \times g$ for $60 \mathrm{~min}$. The particulate fraction was resuspended in $40 \mathrm{mM}$ Tris, pH 7.4 and solubilized with $1 \%$ Lubrol PX. CaM levels were measured by radioimmunoassay (RIA) using CaM antiserum developed in sheep as described [44]. Cytosol samples were heated for $6 \mathrm{~min}$ and particulate fractions were heated for $12 \mathrm{~min}$ before assay. Samples from the 4 treatment groups were always analyzed simultaneously to avoid interassay variability. Statistical significance was determined by one way analysis of variance (ANOVA) with post-analysis Bonferroni $t$-test calculated using GraphPad Instat and by a two-tail Student's $t$-test.

\subsection{Biotinylated-CaM blotting}

Pure bovine testes CaM in $0.1 \mathrm{M}$ phosphate buffer, $\mathrm{pH} 7.4$, with 1 $\mathrm{mM} \mathrm{CaCl}{ }_{2}$ was mixed in a $1: 10$ molar ratio with NHS-LC-biotin in a glass tube for $2 \mathrm{~h}$ at $4^{\circ} \mathrm{C}$. The sample was resuspended to $2 \mathrm{mg} / \mathrm{ml}$, and the protein concentration was determined by A280. Incorporation of biotin was estimated to be $2 \mathrm{~mol}$ of biotin $/ \mathrm{mol}$ of CaM. Biotinylated CaM (BioCaM) overlays were performed according to Billingsley et al. [5]. Incubation with $100 \mu \mathrm{g}$ of BioCaM $/ 5 \mathrm{ml}$ of BioCaM buffer was for 1-2 $\mathrm{h}$ at room temperature. The blots were washed $3 \times 5$ min with BioCaM buffer, and detection of BioCaM was with avidin-alkaline phosphatase. The blot was incubated for $1 \mathrm{~h}$ at $22^{\circ} \mathrm{C}$ with the labeled avidin, washed extensively with BioCaM buffer and developed using Nitro blue tetrazolium and 5-bromo-4-chloro-3indoyl phosphate as substrates. Results were analyzed by scanning the films with a Hoefer GS365W scanning densitometer. The total peak areas were quantified by Gaussian integration using the Hoefer GS365W electrophoresis data system. Peak areas were always compared with those of controls run on the same gel. Statistical significance was determined by one-way analysis of variance (ANOVA) with post-analysis Bonferroni $t$-test calculated using GraphPad Instat.

\subsection{Immunoblotting}

Cell membrane and cytosol fractions were prepared, diluted in sample buffer and separated by SDS-PAGE (7.5\% acrylamide). Proteins were electrophoretically transferred to Immobilon-P mem- 
branes for $2 \mathrm{~h}$ at $1 \mathrm{~A}$ at $4^{\circ} \mathrm{C}$. Blots were incubated in blocking buffer (10 mM Tris, $\mathrm{pH} 7.4,150 \mathrm{mM} \mathrm{NaCl}, 0.1 \%$ Tween 20 and $1 \%(\mathrm{w} / \mathrm{v})$ bovine serum albumin) for $1-2 \mathrm{~h}$ at $4^{\circ} \mathrm{C}$. Antibody against myosin light chain kinase (MLCK) was diluted 1:5000 in blocking buffer and incubated with the blots overnight at $4^{\circ} \mathrm{C}$. ${ }^{125} \mathrm{I}$-labeled goat antimouse secondary antibody or enhanced chemiluminescence (ECL) using horseradish peroxidase (HRP)-conjugated goat antimouse secondary antibody was used for quantification and autoradiography. Results were analyzed by either by scanning the peaks using a Hoefer GS365W scanning densitometer as described above or cutting the $150 \mathrm{kDa}$ band and counting the radioactivity.

\section{A. Striatum}

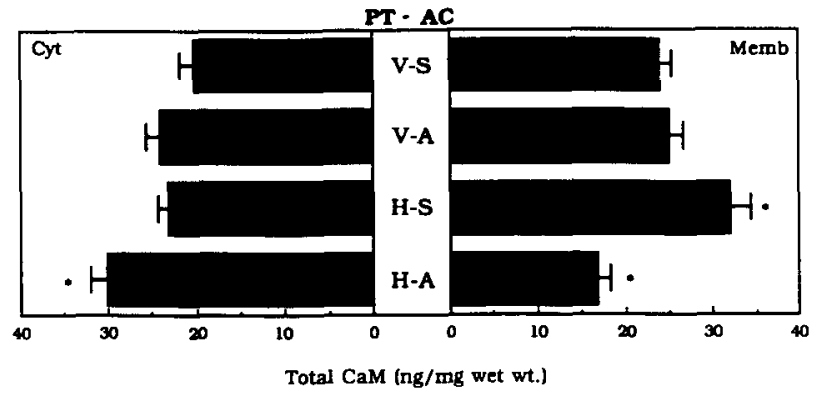

\section{B. Limbic Forebrain}

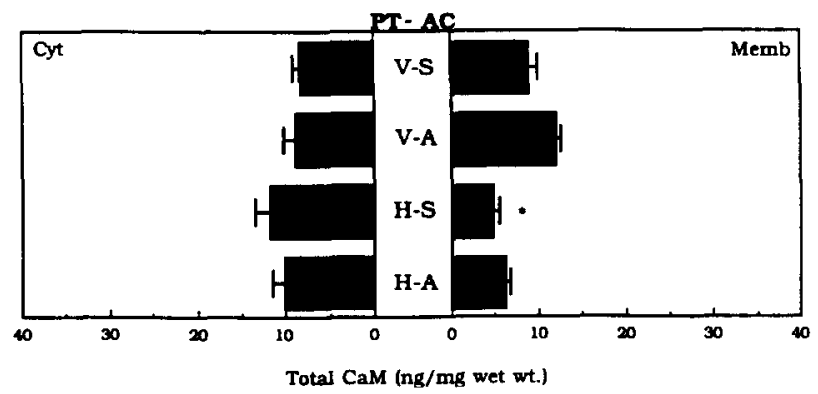

\section{Frontal Cortex}

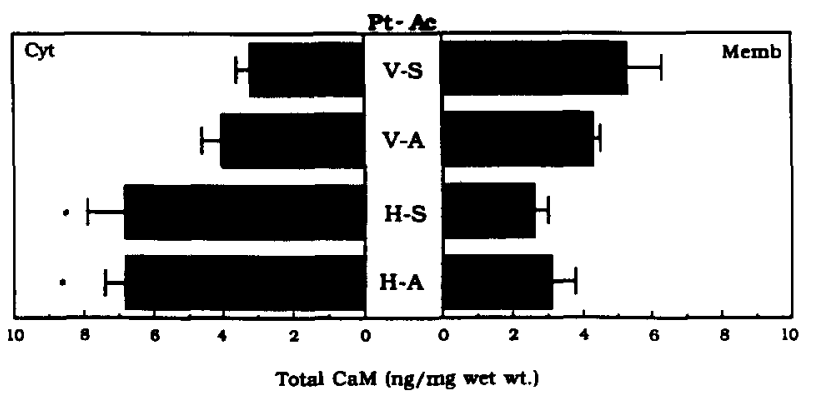

\subsection{Materials}

Haloperidol was graciously donated by McNeil Pharmaceuticals, Fort Washington, PA. Monoclonal antibody to MLCK, leupeptin, pepstatin, phenylmethylsulfonyl fluoride, high molecular weight standards, bovine serum albumin, donkey anti-sheep IgG, HRPlabeled goat antimouse, rice starch, polyethylene glycol 8000 , rabbit serum, Triton X-100, Lubrol PX and Tween 20 were obtained from Sigma Chemical Co. (St. Louis, MO). Immobilon paper was from Millipore (Bedford, MA). ECL reagents were purchased from Amersham (Arlington Heights, IL). ${ }^{125}$ I-goat antimouse and ${ }^{125}$ I-labeled

\section{Hippocampus}

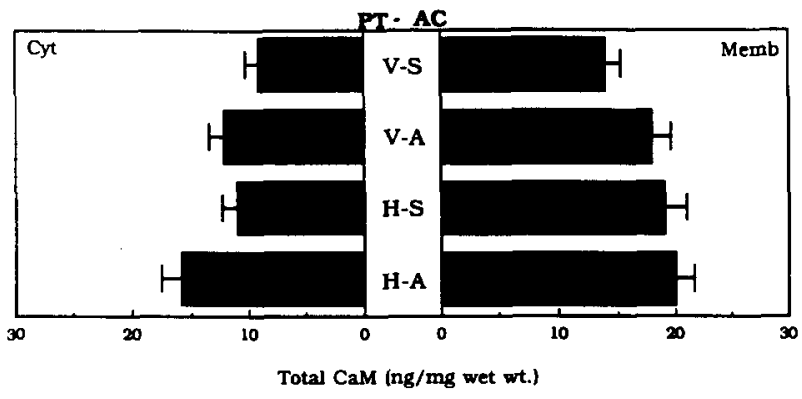

E. Cerebellum

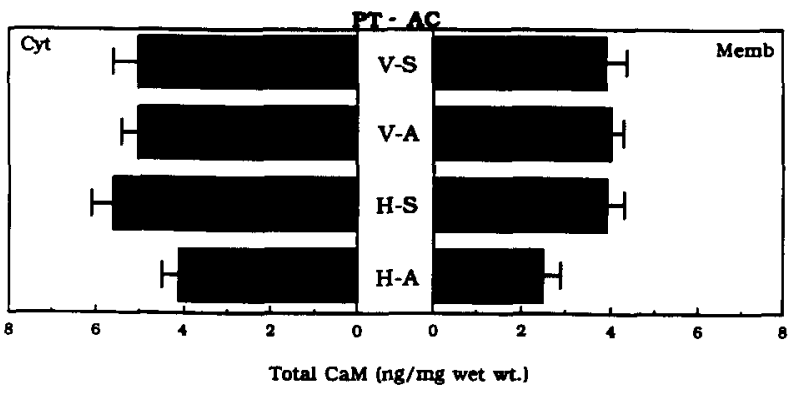

Fig. 1. Effect of repeated HAL and challenge with AMPH on CaM content in subcellular fractions from selected rat brain areas. Male, Sprague-Dawley rats were treated with repeated HAL $(\mathrm{H})$ or vehicle $(\mathrm{V})$ as described in Materials and Methods $(\mathrm{Pt}=$ pretreatment). Four days following the last injection, rats were challenged with acute AMPH (A, $1 \mathrm{mg} / \mathrm{kg}$ i.p.) or saline (S) (Ac = acute) 30 min before sacrifice such that 4 groups were formed: V-S, V-A, H-S, H-A. Striata were homogenized and $100,000 \times g$ cytosol (Cyt) and membrane (Memb) fractions were prepared. Statistical differences were determined by ANOVA and post-analysis Bonferroni $t$-test. (A) Striatum; Cyt.: $P<0.004$ by ANOVA, $P<0.05$ for HA as compared to HS and VS. Memb: $P<0.0001$ by ANOVA, $P<0.001$ for HS as compared to HA, and $P<0.05$ for HS and HA as compared to VS, and for VA as compared to HA. (B) Limbic forebrain; Memb: $P<0.0001, P<0.01$ for HS as compared to VS and VA. (C) Frontal cortex; Cyt: $P<0.006$ by ANOVA, $P<0.05$ for. VS as compared to HS and HA. (D) Hippocampus; Cyt: $P<0.02$ by ANOVA, $P<0.05$ for VS as compared to HA. (E) Cerebellum; no significant values. 
CaM were purchased from NEN Du Pont, Wilmington, DE. AMPH was obtained from University Laboratory of Animal Medicine, University of Michigan, Ann Arbor, MI.

\section{Results}

\subsection{CaM content in rat brain cytosol and membrane fractions 4 days after withdrawal from repeated $H A L$}

The ability of repeated HAL to elicit a change in $\mathrm{CaM}$ content or localization was examined and the specificity of the response for dopaminergic areas in the brain was determined. Sensitivity to a dopamine mimetic agent was evaluated by measuring the ability of a challenge injection of acute AMPH to alter subcellular CaM localization in both VEH- and HAL-pretreatment groups. Rats were treated with HAL $(0.5$ $\mathrm{mg} / \mathrm{kg} \mathrm{s.c.)}$ for 21 days and withdrawn 4 days. In the striatum, repeated HAL induced a significant increase in $\mathrm{CaM}$ in the membrane fraction, as demonstrated previously $[15,18,29,42]$ (Fig. 1A). Challenge with a low dose $(1 \mathrm{mg} / \mathrm{kg})$ of AMPH $30 \mathrm{~min}$ before sacrifice did not alter the distribution of CaM in the VEH-pretreated rats. Consequently the ratio of $\mathrm{CaM}$ content in the membrane to that of cytosol $(\mathrm{M} / \mathrm{C}$ ratio) was constant in VEH-SAL and VEH-AMPH groups (Fig. 2). The distribution of CaM in the HAL-SAL group did not significantly change from that of the VEH-SAL group since a slight but non-significant increase in soluble CaM offset the increase in the membrane. In contrast to its lack of effect in VEH-treated rats, acute AMPH elicited a subcellular redistribution of the CaM in the HAL-treated group. Particulate CaM decreased with a corresponding increase in soluble CaM, signaling a change in sensitivity of the AMPH-induced process mediating translocation in response to repeated haloperidol. This redistribution is reflected as a significant decrease in the $\mathrm{M} / \mathrm{C}$ ratio of $\mathrm{CaM}$ for the HALAMPH group (Fig. 2).

In contrast to the striatum, repeated $\mathrm{HAL}$ altered the subcellular distribution but not the content of CaM in both the limbic forebrain and frontal cortex (Fig. 1B,C). In both areas CaM was increased in the cytosol with a corresponding decrease in the membranes. This was reflected as a significant reduction in the $\mathrm{M} / \mathrm{C}$ ratio for $\mathrm{CaM}$ in both limbic forebrain and frontal cortex as a result of repeated HAL treatment (Fig. 2). A challenge dose of AMPH did not further alter the subcellular localization of $\mathrm{CaM}$ in either VEH- or HAL-pretreated rats (Figs. 1B,C and 2). This suggests that the localization of a 'transferrable' pool of CaM was altered by the repeated HAL treatments and could not be further modified by AMPH.

No changes in CaM content or localization were found in either the hippocampus or cerebellum after repeated HAL treatment (Fig. 1D,E). A challenge dose of AMPH had no effect on CaM localization in either area independent of pretreatment condition (Figs. 1D,E and 2).

\subsection{Haloperidol-induced changes in binding of CaM to CaM-binding proteins}

Since repeated HAL elicited an apparent increase in CaM content in striatum, we investigated whether there was a corresponding change in a CaM-binding protein. Biotinylated $\mathrm{CaM}$ (BioCaM) overlays were used to detect the major CaM binding proteins in the soluble and particulate fractions of control and HALtreated striata from rats that had been withdrawn from drug treatment for 4 days. Major particulate CaMbinding proteins detected by this technique had molecular masses of $270,193,150,130,76,69,49$ and 41

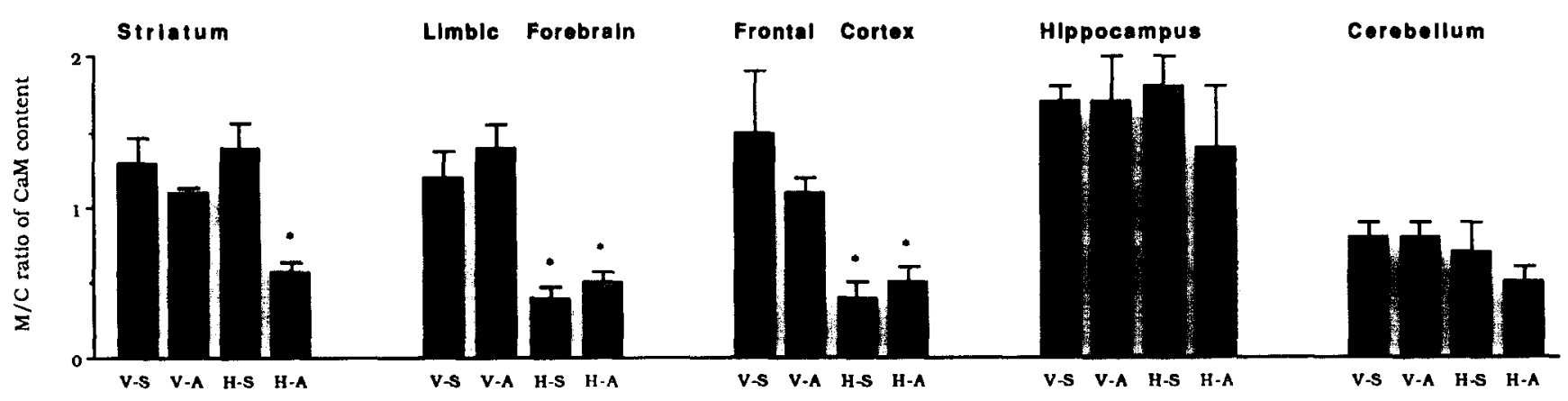

Fig. 2. Membrane/cytosol (M/C) ratio of CaM content in select brain areas from rats pretreated with haloperidol (H) or vehicle (V) and challenged with acute AMPH (A) or saline vehicle (V) $30 \mathrm{~min}$ before sacrifice. Rats were treated and challenged as described in the Legend to Fig. 1. The $\mathrm{M} / \mathrm{C}$ ratio is calculated as the total $\mathrm{CaM}$ content in $\mathrm{ng} \mathrm{CaM} / \mathrm{mg}$ wet wt. (values taken from Fig. 1) in membranes divided by that in cytosol. Results are given as the $\mathrm{M} / \mathrm{C}$ ratio \pm S.E.M. Statistical differences were determined by one-way ANOVA with post-analysis Bonferroni $t$-tests. Striatum: $P<0.0007$ by ANOVA; $P<0.001$ for HS as compared to HA, and $P<0.01$ for VS as compared to HA. Limbic forebrain: $P<0.004$ by ANOVA; $P<05$ for VS as compared to HS and HA, and $P<0.01$ for VA as compared to HS and HA. Frontal cortex: $P<0.005$ by ANOVA; $P<0.05$ for VS as compared to HS and HA, and for VA as compared to HS and HA. Hippocampus and cerebellum: no significant values. 


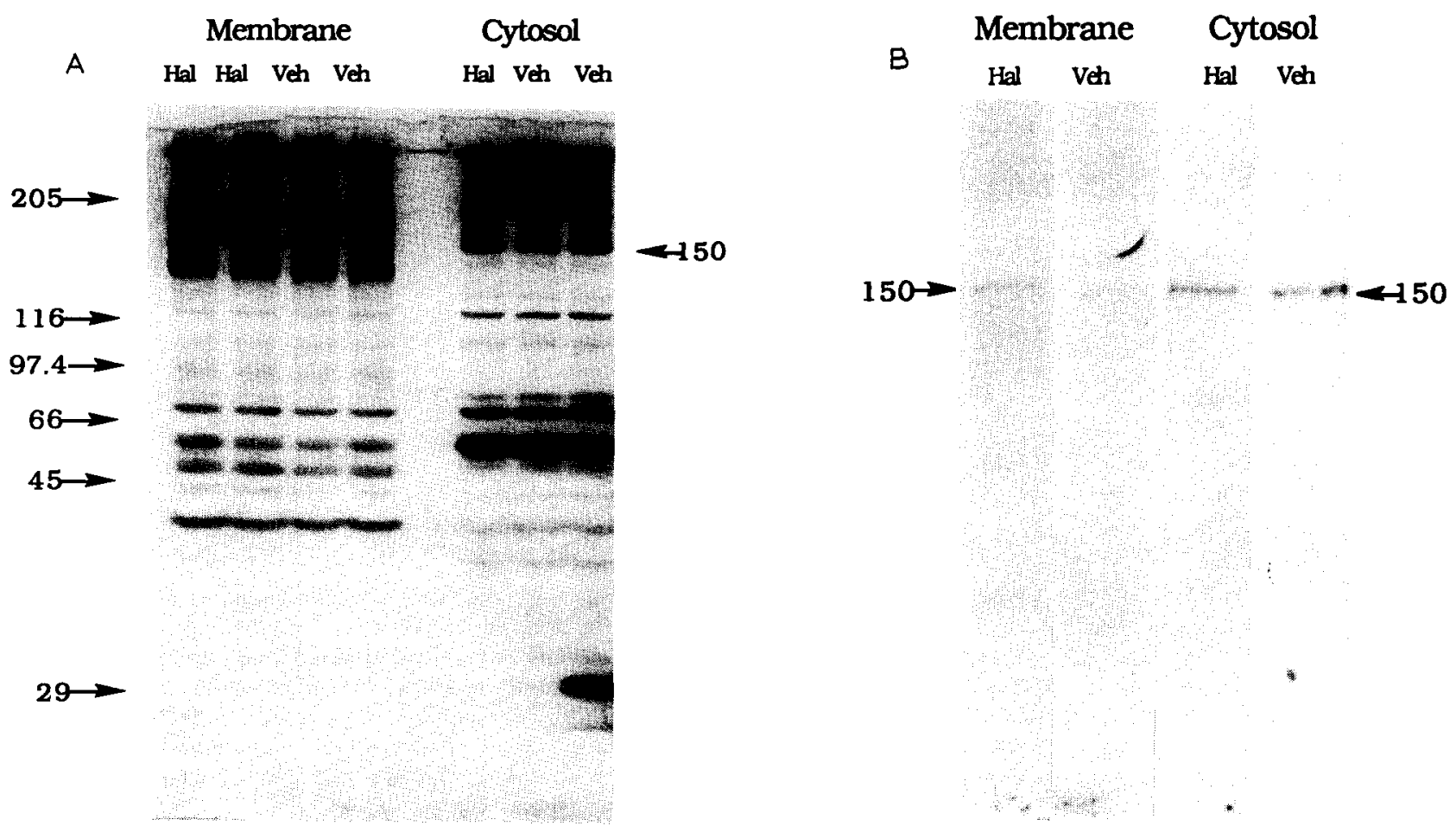

Fig. 3. A: BioCaM blot of CaM-binding proteins in striatal membrane and cytosol fractions from rats treated repeatedly with HAL (Hal) or VEH (Veh). Rats were treated with HAL or VEH as described in Materials and methods. Proteins ( $90 \mu \mathrm{g} /$ lane) were separated on SDS-PAGE (7.5\% acrylamide) and BioCaM blotting was conducted as described in Materials and methods. Blots were developed with avidin alkaline phosphatase. All lanes contained $90 \mu \mathrm{g}$ of protein. Molecular weight markers were (in $\mathrm{kDa}$ ): myosin, 205; $\beta$-galactosidase, 116; phosphorylase B, 97.4 ; bovine serum albumin, 66; ovalbumin, 45; carbonic anhydrase, 29. B: immunoblot detecting MLCK immunoreactivity in striatal cytosol and membrane fractions from rats treated repeatedly with HAL (Hal) or VEH (Veh). Animals were treated and fractions prepared as described in Materials and Methods. Proteins $(100 \mu \mathrm{g} /$ lane) were separated on SDS-PAGE (7.5\% acrylamide) and immunoblotted with mouse anti-MLCK (1:5000). Binding was detected using ${ }^{125}$ I-labeled goat anti-mouse secondary antibody.

kDa. Cytosolic CaM binding proteins included proteins of $270,203,190,150,116,76,58,56,50,40$ and 37 $\mathrm{kDa}$. Binding of biotinylated $\mathrm{CaM}$ to a protein of 150 $\mathrm{kDa}$ showed a significant increase in the striatal membrane fraction after repeated HAL treatment (Figs. 3A and 4). Results from the BioCaM blots were quantified by densitometry as described in Materials and methods. Values from this analysis are presented in Table 1 and demonstrate that the density of the $150 \mathrm{kDa}$ band is significantly greater in striatal particulate fractions from rats treated with HAL. AMPH challenge did not affect the BioCaM binding in either VEH- or HALpretreated groups. In the cytosol fraction, there was a significant decrease in binding of BioCaM to a $150 \mathrm{kDa}$ band but the binding was increased after AMPH challenge (Fig. 4 and Table 1). The decrease in BioCaM

Table 1

BioCaM binding in striatal subcellular fractions from rats treated with vehicle or haloperidol and withdrawn 4 days

\begin{tabular}{llccc}
\hline Fraction & \multicolumn{1}{l}{ Treatment $^{\text {a }}$} & & \\
\cline { 2 - 4 } & VEH-SAL (5) $^{\text {(Densitometry units }\left(\times 10^{-3}\right) \text { ) }}$ & HAL-SAL (5) & HAL-AMPH (4) \\
\hline Membranes $^{b}$ & $4.54 \pm 0.14$ & $4.86 \pm 0.1$ & $5.57 \pm 0.19^{*}$ & $5.37 \pm 0.11^{*}$ \\
Cytosol $^{c}$ & $6.15 \pm 0.40$ & $7.07 \pm 0.46$ & $4.53 \pm 0.40^{*}$ & $6.18 \pm 0.49$
\end{tabular}

\footnotetext{
${ }^{a}$ Male, Sprague-Dawley rats were treated with vehicle (VEH) or haloperidol (HAL) $(0.5 \mathrm{mg} / \mathrm{kg} \mathrm{s.c.}$ ) as described in Materials and Methods and withdrawn 4 days from the drug. Thirty min before sacrifice rats were given a challenge dose of $1 \mathrm{mg} / \mathrm{kg}$ amphetamine (AMPH) i.p. or saline (SAL). The first treatment represents the repeated treatment and the second represents the challenge treatment. Membrane and cytosol fractions were prepared and SDS-PAGE and BioCaM blotting was conducted as described in Materials and methods. The $150 \mathrm{kDa}$ band in the blot was analyzed using densitometry as described in Materials and methods. The $n$ for each group is given in parentheses.

${ }^{b} P<0.0017$ by ANOVA. In post hoc Bonferroni $t$-test, ${ }^{*} P<0.01$ for HAL-SAL and HAL-AMPH as compared to VEH-SAL.

${ }^{\mathrm{c}} P<0.008$ by ANOVA. In post hoc Bonferroni test, ${ }^{*} P<0.01$ for VEH-AMPH as compared to HAL-SAL; $P<0.05$, HAL-AMPH and VEH-SAL as compared to HAL-SAL by post hoc Bonferroni $t$-test.
} 


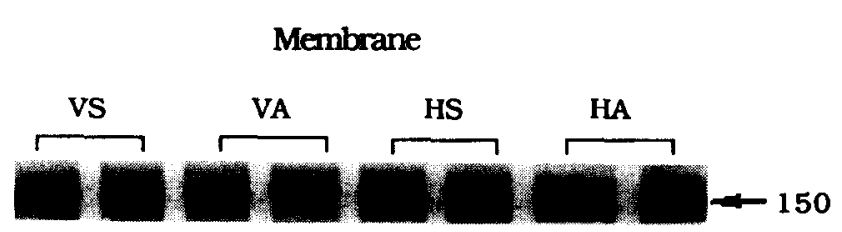

Cytosol

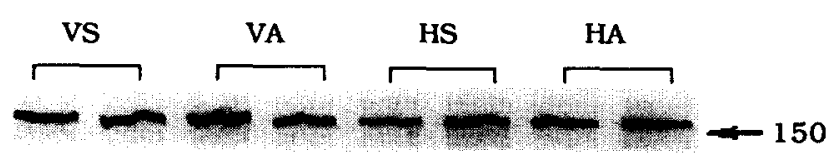

Fig. 4. BioCaM blot of $150 \mathrm{kDa}$ band in striatal membrane and cytosol fractions from rats treated repeatedly with HAL (H) or VEH (V). Four days following the last injection, rats were challenged with acute AMPH (A, $1 \mathrm{mg} / \mathrm{kg}$ i.p.) or saline (S) $30 \mathrm{~min}$ before sacrifice such that 4 groups were formed: V-S, V-A, H-S, H-A. Proteins were separated by SDS-PAGE and subjected to BioCaM blotting as described in Materials and methods and the legend to Fig. 3. In these experiments, gels with the membrane fractions contained 200 $\mu \mathrm{g} /$ lane while those with cytosol fractions contained $100 \mu \mathrm{g} /$ lane. Blots were developed with avidin alkaline phosphatase.

binding in the cytosol of the HAL-SAL group was not spurious since it was reproduced in another group of repeated HAL-treated rats withdrawn 4 days.

A known CaM-binding protein in brain of approximately $150 \mathrm{kDa}$ is myosin light chain kinase (MLCK). To determine whether there was an alteration in MLCK that would correspond with changes in BioCaM labeling, immunoblots were performed on the fractions using a monoclonal antibody to MLCK. MLCK immunoreactivity was detected in both striatal particulate and supernatant fractions at the same apparent molecular size as the $150 \mathrm{kDa}$ BioCaM binding protein. Note that both the BioCaM labeling of the $150 \mathrm{kDa}$ band and the MLCK immunoreactivity labeling is greater in

Table 2

MLCK immunoreactivity in striatal subcellular fractions from rats treated with vehicle or haloperidol and withdrawn 4 days

\begin{tabular}{|c|c|c|c|}
\hline \multirow[t]{2}{*}{ Fraction } & \multicolumn{3}{|l|}{ Treatment $^{\mathbf{a}}$} \\
\hline & $\begin{array}{l}\text { VEH-SAL VEH-AMPH } \\
\text { (Densitometry units }(\times 10\end{array}$ & $\begin{array}{l}\text { HAL-SAL } \\
\left.\left(1^{-3}\right)\right)\end{array}$ & $\overline{\text { HAL-AMPH }}$ \\
\hline Membranes ${ }^{b}$ & $10.4 \pm 0.7 \quad 10.9 \pm 1.0$ & $15.0 \pm 1.3^{*}$ & $15.5 \pm 1.6$ \\
\hline Cytosol & $22.2 \pm 3.2 \quad 19.8 \pm 1.4$ & $20.9 \pm 1.4$ & $16.3 \pm 2.5$ \\
\hline
\end{tabular}

${ }^{a}$ Rats were treated as described in the legend to Fig. 1 and Table 1. Immunoblotting was performed as described in Materials and methods. Blots were developed using goat antimouse and ECL. Results were analyzed using densitometry as described in Materials and methods. For all groups, $n=5$.

${ }^{\mathrm{b}} P<0.02$, for ANOVA, ${ }^{*} P<0.05$ by post hoc Bonferroni $t$-test for HAL-SAL and HAL-AMPH as compared to VEH-SAL.

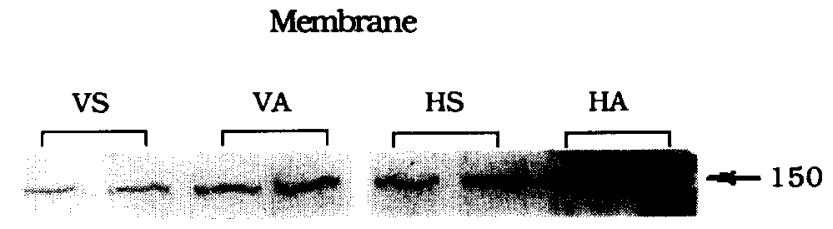

Cytosol

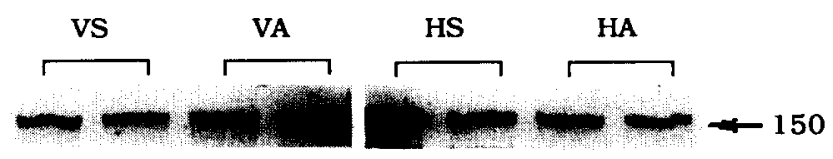

Fig. 5. Immunoblot detecting MLCK immunoreactivity in striatal cytosol and membrane fractions from rats treated repeatedly with HAL (H) or VEH (V) and withdrawn 4 days. Animals were challenged with saline (S) or AMPH (A) before sacrifice as described in the legend to Fig. 4. Proteins were separated by SDS-PAGE $(7.5 \%$ polyacrylamide) and immunoblotted with mouse anti-MLCK $(1: 5000)$. All lanes, for membrane and cytosol, contained $100 \mu \mathrm{g}$ of protein. Binding was detected with ECL.

the cytosol fraction than in the membrane fraction when equal amounts of soluble and particulate protein are loaded on the gels (Fig. 3A,B). In brain, approximately $70 \%$ of MLCK is located in the cytosol [3]. As shown in Fig. 3B, no other proteins were labeled with the MLCK antibody. Results were verified with an antibody to bovine trachea MLCK generously donated by Dr. James Stull, University of Texas at Dallas. As shown in Fig. 5 and Table 2, there was a significant increase in MLCK immunoreactivity (MLCK-ir) in striatal particulate fractions from HAL-treated rats. Challenge with AMPH produced no change in MLCK-ir. In contrast to the BioCaM labeling (Figs. 3 and 4 and Table 1) there was no change in MLCK-ir in striatal cytosol fractions from HAL-treated animals independent of AMPH challenge (Fig. 5 and Table 2).

In order to determine whether the change in Bio$\mathrm{CaM}$ binding and MLCK-ir persist for a longer time after withdrawal from HAL, these parameters were

Table 3

MLCK immunoreactivity in striatal subcellular fractions from rats treated with vehicle or haloperidol and withdrawn 10 days

\begin{tabular}{lcl}
\hline Fraction & \multicolumn{2}{|c}{ Treatment $^{\text {a }}$} \\
\cline { 2 - 3 } & $\begin{array}{l}\text { VEH } \\
\text { (cpm) }\end{array}$ & $\begin{array}{l}\text { HAL } \\
\text { (cpm) }\end{array}$ \\
\hline Membranes & $90 \pm 14$ & $280 \pm 51^{\text {b }}$ \\
Cytosol & $396 \pm 25$ & $446 \pm 164$ \\
\hline
\end{tabular}

${ }^{a}$ Rats were treated and gel electrophoresis performed as described in legend to Table 3. Bands were cut and counted.

${ }^{\mathrm{b}} P<0.005$ for HAL membranes as compared to VEH controls, by 2-tail Students $t$-test. 


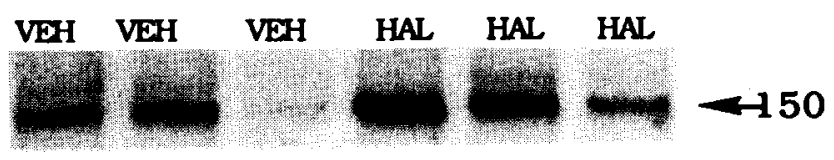

Fig. 6. Immunoblot detecting MLCK immunoreactivity in striatal membrane fractions from rats treated repeatedly with HAL or VEH and withdrawn 10 days. Proteins were separated by SDS-PAGE (7.5\% polyacrylamide) and immunoblotted with mouse anti-MLCK (1:5000). All lanes, for membrane and cytosol, contained $200 \mu \mathrm{g}$ of protein. Binding was detected with ${ }^{125} \mathrm{I}$-labeled goat anti-mouse secondary antibody. Labeled bands were cut and counted and the results are given in Table 3.

measured in rats that were withdrawn 10 days from repeated HAL. There were no challenge groups in this experiment. In accordance with the 4 day withdrawal group, there was a significant increase in MLCK-ir measured in striatal particulate fractions from HALtreated rats (Fig. 6). In these experiments, MLCK-ir was detected with ${ }^{125}$ I-labeled secondary antibody; the bands demonstrating MLCK-ir were cut and counted and the results are shown in Table 3 . There is a highly significant increase in CPM from the $150 \mathrm{kDa}$-labeled band in the striatal particulate fraction but no significant change in the soluble fraction. The large standard error of the means in the soluble fraction in the HALtreated group is due to a very high value in the HALtreated group.

\section{Discussion}

This and previous studies [15,18,29,42] have demonstrated that repeated HAL treatment increases CaM content in the particulate fraction in rat striatum. To examine whether striatal CaM-binding proteins are concomitantly altered, binding of biotinylated CaM to striatal proteins was assessed. This report is the first to identify a change in a CaM-binding protein, which appears to be MLCK, accompanying the increase in $\mathrm{CaM}$ in response to haloperidol treatment. Increases in CaM-binding proteins paralleling hormone or neurotransmitter-induced increases in CaM have been reported [14]. In many cases the CaM-binding protein involved was MLCK. In rabbit myometrium, a cycloheximide-sensitive increase in MLCK activity paralleled the increase in CaM after estrogen or progesterone treatment [33]. Alpha1 adrenergic receptormediated release of $\mathrm{Ca}^{2+}$ from the endoplasmic reticulum during proliferative activation of rat liver elicited a translocation of cytosolic CaM into the nucleus that was accompanied by an increase in nuclear content of two CaM-binding proteins believed to be $\alpha$-spectrin and MLCK [43]. Estrogen treatment of immature chickens resulted in an enrichment of MLCK in the liver nuclear matrix [50]. Expression of some CaMbinding proteins, such as CaM-sensitive phosphodiesterase and CaM-kinase II have been altered by transsynaptic regulation, especially denervation or synaptic deprivation [2,21,54]. Repeated HAL did not alter CaM-binding proteins in developing rat striatum [40]. Either the effect is specific for plasticity changes in the adult or factors such as withdrawal time could account for the difference. MLCK, demonstrating an apparent $M_{\mathrm{r}}$ of 150,000 , has been purified from brain and identified in both cytosol and particulate fractions with approximately $69 \%$ of the activity in the cytosol [3]. In our experiments, both MLCK immunoreactivity (-ir) and BioCaM binding to a $150,000 \mathrm{kDa}$ band is greater in the $100,000 \times g$ cytosol than in the pellet. MLCK has been found in both neurons and glia in cytosol and cytoskeleton [10].

The increase in MLCK-ir could be due to an increase in the amount of protein or an alteration in conformation of the protein leading to a change in immunodetectability. In general, the binding of Bio$\mathrm{CaM}$ to the $150 \mathrm{kDa}$ band correlated fairly well with MLCK-ir, with the exception of the cytosol in HALtreated rats receiving a VEH challenge dose. In these samples, the levels of BioCaM binding were significantly decreased as compared to VEH-treated controls but increased after challenge with AMPH (the HALAMPH group). It is unlikely that this represents a simple translocation of $150 \mathrm{kDa}$ protein from cytosol to membranes since there was no corresponding change in labeling of the $150 \mathrm{kDa}$ binding in membrane after AMPH challenge. In addition, there was no significant change in MLCK-ir in the cytosol fractions. Alterations in BioCaM binding, however, could represent a change in affinity of $\mathrm{CaM}$ for the protein in addition to a change in amount of immunodetectible MLCK. MLCK is phosphorylated by protein kinase A, protein kinase $\mathrm{C}$ and CaM-Kinase II at a specific site (site A), which reduces the sensitivity of the enzyme for CaM 10- to 20 -fold [8,51]. Thus, the decrease in BioCaM binding could represent a change in phosphorylation or some other modification of MLCK that would reduce binding. Challenge with AMPH could reverse the modification restoring control levels of BioCaM binding to the $150 \mathrm{kDa}$ protein.

The altered localization or content of $\mathrm{CaM}$ induced by repeated HAL could more generally signal an increase in $\mathrm{Ca}^{2+}$ sensitivity of CaM-dependent target enzymes and/or a change in organization of CaMbinding cytoskeletal proteins. The 33\% increase in $\mathrm{CaM}$ in the striatum is modest but a small change in $\mathrm{CaM}$ could have profound effects on the activity and sensitivity of $\mathrm{Ca}^{2+}$ signal transduction events. $\mathrm{CaM}$ and $\mathrm{Ca}^{2+}$ synergistically activate several target proteins, including MLCK, such that the affinity of the enzyme for one ligand is greatly enhanced by the presence of 
the other $[9,39]$. The repeated HAL-induced increase in membrane $\mathrm{CaM}$ suggests that the activity of membrane-localized CaM-dependent processes could be increased. Several CaM-dependent enzymes such as $\mathrm{Ca}^{2+}, \mathrm{Mg}^{2+}$, ATPase and adenylyl cyclase partition into the membranes along with CaM-binding cytoskeletal and membrane proteins. On the contrary, the HAL-induced increase in soluble $\mathrm{CaM}$ in limbic forebrain or frontal cortex suggests a potential increase in $\mathrm{Ca}^{2+}$ sensitivity of soluble CaM-binding target enzymes. A change in soluble CaM could also suggest a rearrangement of $\mathrm{CaM}$ binding to the cytoskeleton or membrane skeleton such that it partitions more readily into the cytosol upon homogenization. These considerations would similarly apply to a stimulus-induced increase in soluble CaM, such as that induced by AMPH challenge.

In contrast to the increase in particulate $\mathrm{CaM}$ in the striatum, repeated HAL treatment altered the subcellular location of $\mathrm{CaM}$ in the limbic forebrain and frontal cortex without changing the total $\mathrm{CaM}$. This could reflect a differential effect of the repeated HAL on dopamine levels and turnover in these regions $[11,22,27,49]$, or differential expressions of plasticity due to dissimilar neuronal organization. The limbic forebrain and frontal cortex are considered to be important sites for antipsychotic activity of the drugs while striatum may contribute more to their motor side effects [6]. The differential responsiveness of the striatum was also shown by the fact that, in HAL-treated rats, challenge with a lower dose of AMPH $(1 \mathrm{mg} / \mathrm{kg})$ elicited a translocation of $\mathrm{CaM}$ in striatum but not in limbic forebrain or frontal cortex. See et al. [49] found an enhanced response of dopamine activity to AMPH in the striatum but not nucleus accumbens in rats treated chronically with HAL. Repeated HAL-induced increases in particulate rat striatal CaM have been repeatedly demonstrated $[15,18,29,42]$ but results in other dopaminergic areas have been equivocal. Popov et al. [42] found no significant change in nucleus accumbens but a decrease in soluble CaM in the hippocampus. The differences from our results could be accounted for by differences in drug treatment and withdrawal times. We treated rats with $0.5 \mathrm{mg} / \mathrm{kg}$ HAL subcutaneously for 21 days with 4 days of withdrawal while Popov et al. treated rats for 21 days with $1 \mathrm{mg} / \mathrm{kg}$ HAL i.p. with 2 days withdrawal. We previously showed that the repeated HAL-induced increase in striatal CaM is not apparent upon cessation of drug treatment and takes time after withdrawal to appear [15]. It is possible that longer withdrawal times are required to detect changes in limbic forebrain $\mathrm{CaM}$, and higher doses of HAL are necessary to detect decreased CaM in the hippocampus.

The fact that AMPH challenge induced a translocation of CaM from membranes to cytosol in striatum in
HAL- but not VEH-pretreated rats suggests an enhanced sensitivity of the release process in repeated HAL-treated rats. AMPH has been shown to redistribute CaM in non-treated rats but the dose of AMPH in this study may be slightly lower than that used in others $[18,41]$. In addition, in our chronic study, the VEH-treated rats had been repeatedly handled which may alter the sensitivity of the process. Translocation of $\mathrm{CaM}$ from membranes to cytosol has been correlated with a decreased responsiveness of adenylyl cyclase to dopamine [16,35] and an enhanced activation of CaM-sensitive cAMP-dependent phosphodiesterase [18]. In rats behaviorally sensitized to AMPH but not in SAL controls, challenge with $1 \mathrm{mg} / \mathrm{kg}$ of AMPH actively redistributed striatal $\mathrm{CaM}$ to the cytosol with a concomitant reduction in activation of striatal adenylyl cyclase by the $D_{1}$ dopamine agonist, SKF 38393 [46]. The development of $D_{1}$ dopamine receptor sensitivity after chronic antipsychotic treatment is controversial. There appears to be no increase in binding to $D_{1}$ dopamine receptors [31], although enhanced sensitivity of adenylyl cyclase to DA and GTP has been reported $[15,23,36,48,53]$.

The changes in CaM are withdrawal-dependent suggesting that the alterations in $\mathrm{CaM}$ are compensatory responses to drug treatment. Since alterations in $\mathrm{CaM}$ have been detected after repeated treatment with other psychoactive drugs such as AMPH, cocaine and morphine $[14,18,42]$, it is possible that the alteration in $\mathrm{CaM}$ is a general response to altered synaptic activity and is more generally related to drug-induced plasticity. Repeated treatment with AMPH, morphine and cocaine results in a behaviorally manifested sensitization to dopaminergic drugs $[1,45]$. CaM could play a role in several neurochemical changes reported to result from repeated treatment with psychoactive drugs, such as an increase in stimulus-induced neurotransmitter release [17] or morphological changes in synaptic structures, both of which involve cytoskeletal interactions [30]. Morphometric studies in rat striatum and frontal cortex have shown synaptic changes after repeated HAL treatment consistent with enhanced growth and possible sprouting of presynaptic neurons as well as induced postsynaptic plastic changes involving dendritic spines [4,24-26]. Dynamic changes in cytoskeletal proteins are proposed to regulate the shape of nerve cells and synapses as well as the movement of cytosolic components within the cell, processes known to involve $\mathrm{Ca}^{2+}[12,30]$. Actin and myosin have been localized to the dendritic spine plasma membrane in several brain areas [12]. Drug-induced changes in MLCK could enhance myosin-actin interactions, inducing movement of cytoplasm within the spine aiding morphological changes. There is anatomical specificity in the effects of HAL on ultrastructure. Repeated HAL increased the number of perforated synapses in 
caudate but not nucleus accumbens [37]. Some changes in CaM location and content could be due to the differential effects on morphology. Therefore, an increase in CaM and CaM-binding proteins could be involved with neurochemical or morphological alterations in the synapse that contribute to sensitization.

In conclusion, we have demonstrated a change in CaM content or localization in response to repeated HAL treatment in brain areas enriched in dopaminergic innervation. Accompanying the increase in striatal CaM content is an increase in detectible MLCK-ir. Enhanced dopaminergic responsivity in the striatum was suggested by the fact that an AMPH challenge elicited a translocation of $\mathrm{CaM}$ in striatum from repeated HAL-treated rats and not from vehicle-treated rats. In HAL-treated animals, therefore, dopaminergic activity would lead to enhanced activation of cytosolic $\mathrm{CaM}$ target proteins due to redistribution of $\mathrm{CaM}$ to the cytosol. The increase in CaM and MLCK may signal a greatly enhanced sensitivity of actin myosin interactions after repeated HAL that could contribute to HAL-induced morphological changes or other HAL-induced changes in synaptic plasticity.

\section{Acknowledgements}

This work was supported by National Institutes of Health Grant MH36044.

\section{References}

[1] Antelman, S.M., Stressor-induced sensitization to subsequent stress: implications for the development and treatment of clinical disorders. In P.W. Kalivas and C.D. Barnes (Eds.), Sensitization in the Nervous System, Telford Pr., Caldwell, NJ, 1988, pp. 228-254.

[2] Balaban, C.D., Billingsley, M.L. and Kincaid, R.L., Evidence for transsynaptic regulation of calmodulin-dependent cyclic nucleotide phosphodiesterase in cerebellar Purkinje cells, J. Neurosci., 9 (1989) 2374-2381.

[3] Bartelt, D.C., Moroney, S. and Wolff, D.J., Purification, characterization and substrate specificity of calmodulin-dependent myosin light-chain kinase from bovine brain, Biochem. J., 247 (1987) 747-756.

[4] Benes, F.M., Paskevich, P.A., Davidson, J. and Domesick, V.B., The effects of haloperidol on synaptic patterns in the rat striatum, Brain Res., 329 (1985) 265-274.

[5] Billingsley, M.L., Pennypacker, K.R., Hoover, C.G., Brigati, D.J. and Kincaid, R.L., A rapid and sensitive method for detection and quantification of calcineurin and calmodulin-binding proteins using biotinylated calmodulin, Proc. Natl. Acad. Sci. USA, 82 (1985) 7585-7589.

[6] Bowers, M.B., Jr., Biochemical processes in schizophrenia: an update, Schizophrenia Bull., 6 (1980) 393-403.

[7] Burt, D.R., Creese, I. and Snyder, S.H., Antischizophrenic drugs: chronic treatment elevates dopamine receptor binding in brain, Science, 196 (1977) 326-328.
[8] Conti, M.A. and Adelstein, R.S., The relationship between calmodulin binding and phosphorylation of smooth muscle myosin kinase by the catalytic subunit of $3^{\prime}: 5^{\prime}$ cAMP-dependent protein kinase, J. Biol. Chem., 256 (1981) 3178-3181.

[9] Cox, J.A., Interactive properties of calmodulin, Biochem. J., 249 (1988) 621-629.

[10] Edelman, A.M., Higgins, D.M., Bowman, C.L., Haber, S.N., Rabin, R.A. and Cho-Lee, J., Myosin light chain kinase is expressed in neurons and glia: Immunoblotting and immunocytochemical studies, Mol. Brain Res., 14 (1992) 27-34.

[11] Egan, M.F., Karoum, F. and Wyatt, R.J., Effects of acute and chronic clozapine and haloperidol administration on 3methoxytyramine accumulation in rat prefrontal cortex, nucleus accumbens and striatum, Eur. J. Pharmacol., 199 (1991) 191-199.

[12] Fifkova, E. and Morales, M., Calcium-regulated contractile and cytoskeletal proteins in dendritic spines may control synaptic plasticity, Ann. NY Acad. Sci., 568 (1989) 131-137.

[13] Gnegy, M. and Treisman, G., Effect of calmodulin on dopamine-sensitive adenylate cyclase activity in rat striatal membranes, Mol. Pharmacol., 19 (1981) 256-263.

[14] Gnegy, M.E., Calmodulin in Neurotransmitter and Hormone Action, Annu. Rev. Pharmacol. Toxicol., 32 (1993) 45-70.

[15] Gnegy, M.E., Lucchelli, A. and Costa, E., Correlation between drug-induced supersensitivity of dopamine dependent striatal mechanisms and the increase in striatal content of the $\mathrm{Ca}^{2+}$ regulated protein activator of cAMP phosphodiesterase, Naunyn-Schmiedebergs. Arch. Pharmacol, 301 (1977) 121-127.

[16] Gnegy, M.E., Uzunov, P. and Costa, E., Regulation of the dopamine stimulation of striatal adenylate cyclase by an endogenous $\mathrm{Ca}^{2+}$-binding protein, Proc. Natl. Acad. Sci. USA, 73 (1976) 3887-3890.

[17] Greengard, P., Valtorta, F., Czernik, A.J. and Benfenati, F., Synaptic vesicle phosphoproteins and regulation of synaptic function, Science, 259 (1993) 780-785.

[18] Hanbauer, I., Pradham, S. and Yang, H.-Y.T., Role of calmodulin in dopaminergic transmission, Ann. NY Acad. Sci., 356 (1980) 292-303.

[19] Harrison, J.K., Mickevicius, C.K. and Gnegy, M.E., Differential regulation by calmodulin of basal, GTP-and dopamine-stimulated adenylate cyclase activities in bovine striatum, $J$. Neurochem., 51 (1988) 345-352.

[20] Heffner, T.G., Hartman, J.A. and Seiden, L.S., A rapid method for the regional dissection of the rat brain, Pharmacol. Biochem. Behav., 13 (1980) 453-456.

[21] Hendry, S.H. and Kennedy, M.B., Immunoreactivity for a calmodulin-dependent protein kinase is selectively increased in macaque striate cortex after monocular deprivation, Proc. Natl. Acad. Sci. USA, 83 (1986) 1536-1541.

[22] Hernandez, L. and Hoebel, B.G., Haloperidol given chronically decreases basal dopamine in the prefrontal cortex more than the striatum or nucleus accumbens as simultaneously measured by microdialysis, Brain Res. Bull., 22 (1989) 763-769.

[23] Iwatsubo, K. and Clouet, D.H., Dopamine-sensitive adenylate cyclase of the caudate nucleus of rats treated with morphine or haloperidol, Biochem. Pharmacol, 24 (1975) 1499-1503.

[24] Kerns, J.M., Sierens, D.K., Kao, L.C., Klawans, H.L. and Carvey, P.M., Synaptic plasticity in the rat striatum following chronic haloperidol treatment, Clin. Neuropharmacol, 15 (1992) 488500.

[25] Klintzova, A.J., Haselhorst, U., Uranova, N.A., Schenk, H. and Istomin, V.V., The effects of haloperidol on synaptic plasticity in rat's medial prefrontal cortex, J. Hirnforsch., 30 (1989) 51-57.

[26] Klintzova, A.J., Uranova, N.A., Haselhorst, U. and Schenk, H., Synaptic plasticity in rat medial prefrontal cortex under chronic haloperidol treatment produced behavioral sensitization, $J$. Hirnforsch., 31 (1990) 175-179. 
[27] Kurata, K. and Shibata, R., Differential effect of haloperidol on dopamine release and metabolism in caudate putamen and anteromedial frontal cortex using intracerebral dialysis, Pharmacology, 42 (1991) 1-9.

[28] Lau, Y.-S., Increase of calmodulin-stimulated striatal particulate phosphorylation response in chronic haloperidol-treated rats, Brain Res., 307 (1984) 181-189.

[29] Lucchelli, A., Guidotti, A. and Costa, E., Striatal content of $\mathrm{Ca}^{2+}$-dependent regulator protein and dopaminergic receptor function, Brain Res., 155 (1978) 130-135.

[30] Lynch, G. and Baudry, M., Brain spectrin, calpain and long-term changes in synaptic efficacy, Brain Res. Bull., 18 (1987) 809-815.

[31] MacKenzie, R.G. and Zigmond, M.J., Chronic neuroleptic treatment increases D-2 but not D-1 receptors in rat striatum, Eur. J. Pharmacol., 113 (1985) 159-165.

[32] Manalan, A.S. and Klee, C.B., Calmodulin, Adv. Cyclic Nucl. Protein Phosphor. Res., 18 (1984) 227-278.

[33] Matsui, K., Higashi, K., Fukunaga, K., Miyazaki, K., Maeyama, $M$. and Miyamoto, E., Hormone treatments and pregnancy alter myosin light chain kinase and calmodulin levels in rabbit myometrium, J. Endocrinol., 97 (1983) 11-19.

[34] Means, A.R., VanBerkum, M.F.A., Bagchi, I., Lu, K.P. and Rasmussen, C.D., Regulatory functions of calmodulin, Pharmacol. Ther, 50 (1991) 255-270.

[35] Memo, M., Lovenberg, W. and Hanbauer, I., Agonist-induced subsensitivity of adenylate cyclase coupled with a dopamine receptor in slices from rat corpus striatum, Proc. Natl. Acad. Sci. USA, 79 (1982) 4456-4460.

[36] Memo, M., Pizzi, M., Missale, C., Carruba, M.O. and Spano, P.F., Modification of the function of D1 and D2 dopamine receptors in striatum and nucleus accumbens of rats chronically treated with haloperidol, Neuropharmacology, 26 (1987) 477480 .

[37] Meshul, C.K., Janowsky, A., Casey, D.E., Stallbaumer, R.K. and Taylor, B., Coadministration of haloperidol and SCH-23390 prevents the increase in 'perforated' synapses due to either drug alone, Neuropsychopharmacology, 7 (1992) 285-293.

[38] Natsukari, N., Hanai, H., Matsunaga, T. and Fujita, M., Synergistic activation of brain adenylate cyclase by calmodulin, and either GTP or catecholamines including dopamine, Brain Res., 534 (1990) 170-176.

[39] Olwin, B.B., Edelman, A.M., Krebs, E.G. and Storm, D.R., Quantitation of energy coupling between $\mathrm{Ca}^{2+}$, calmodulin, skeletal muscle myosin light chain kinase, and kinase substrates, J. Biol. Chem., 259 (1984) 10949-10955.

[40] Polli, J.W., Billingsley, M.L. and Kincaid, R.L., Expression of the calmodulin-dependent protein phosphatase, calcineurin, in rat brain: developmental patterns and the role of nigrostriatal innervation, Dev. Brain Res., 63 (1991) 105-119.

[41] Popov, N. and Matthies, H., Influence of dopamine receptor agonists and antagonists on calmodulin translocation in different brain regions, Eur. J. Pharmacol., 172 (1989) 205-210.

[42] Popov, N., Schulzeck, S., Nuss, D., Vopel, A.-U., Jendrny, C., Struy, H. and Matthies, H., Alterations in calmodulin content of rat brain areas after chronic application of haloperidol and amphetamine, Biomed. Biochim. Acta, 47 (1988) 435-441.

[43] Pujol, M.J., Soriano, M., Aligue, R., Carafoli, E. and Bachs, O., Effect of alpha-adrenergic blockers on calmodulin association with the nuclear matrix of rat liver cells during proliferative activation, J. Biol. Chem., 264 (1989) 18863-18865.

[44] Roberts-Lewis, J.M., Welsh, M.J. and Gnegy, M.E., Chronic amphetamine treatment increases striatal calmodulin in rats. Brain Res., 384 (1986) 383-386.

[45] Robinson, T.E., The neurobiology of amphetamine psychosis: Evidence from studies with an animal model. In T. Nakazawa (Ed.) Taniguchi Symposia on Brain Sciences, Vol. 14, Biological Basis of Schizophrenic Disorders, Japan Scientific Societies Press, Tokyo, 1991, pp. 185-201.

[46] Roseboom, P.H., Hewlett, G.H.K. and Gnegy, M.E., Repeated amphetamine administration alters the interaction between D1stimulated adenylyl cyclase activity and calmodulin in rat striatum, J. Pharmacol. Exp. Ther., 255 (1990) 197-203.

[47] Saller, C.F. and Salama, A.I., Alterations in dopamine metabolism after chronic administration of haloperidol. Possible role of increased autoreceptor sensitivity, Neuropharmacology, 24 (1985) 123-129.

[48] Schettini, G., Ventra, C., Florio, T., Grimaldi, M., Meucci, O. and Marino, A., Modulation by GTP of basal and agoniststimulated striatal adenylate cyclase activity following chronic blockade of D1 and D2 dopamine receptors: involvement of $G$ proteins in the development of receptor supersensitivity, $J$. Neurochem., 59 (1992) 1667-1674.

[49] See, R.E., Chapman, M.A., Murray, C.E. and Aravagiri, M., Regional differences in chronic neuroleptic effects on extracellular dopamine activity, Brain Res. Bull., 29 (1992) 473-478.

[50] Simmen, R.C., Dunbar, B.S., Guerriero, V., Chafouleas, J.G., Clark, J.H. and Means, A.R., Estrogen stimulates the transient association of calmodulin and myosin light chain kinase with the chicken liver nuclear matrix, J. Cell Biol., 99 (1984) 588-593.

[51] Stull, J.T., Hsu, L.C., Tansey, M.G. and Kamm, K.E., Myosin light chain kinase phosphorylation in tracheal smooth muscle, $J$. Biol. Chem., 265 (1990) 16683-16690.

[52] Tarsy, D. and Baldessarini, R.J., Behavioral supersensitivity to apomorphine following chronic treatment with drugs which interfere with the synaptic function of catecholamines, Neuropharmacology, 13 (1974) 927-940.

[53] Treisman, G.J., Muirhead, N. and Gnegy, M.E., Increased sensitivity of adenylate cyclase activity in the striatum of the rat to calmodulin and GppNHp after chronic treatment with haloperidol, Neuropharmacology, 25 (1986) 587-595.

[54] Wu, K. and Black, I.B., Regulation of molecular components of the synapse in the developing and adult rat superior cervical ganglion, Proc. Natl. Acad. Sci. USA, 84 (1987) 8687-8691.

[55] Yamada, S., Yokoo, H. and Nishi, S., Chronic treatment with haloperidol modifies the sensitivity of autoreceptors that modulate dopamine release in rat striatum, Eur. J. Pharmacol, 232 (1993) $1-6$. 